\title{
HUBUNGAN POLA MAKAN DAN AKTIVITAS FISIK DENGAN PENGENDALIAN KADAR GULA DARAH PADA PENDERITA DIABETES MELLITUS TIPE II DI WILAYAH KERJA PUSKESMAS KTK KOTA SOLOK
}

\section{NETTY HERAWATI, KURNIATI MAYA SARI WD}

Akademi Keperawatan YPTK Solok

\begin{abstract}
Controlling blood sugar levels is the main goal of nursing interventions that will be carried out in Diabetes Mellitus patients. Patients with diabetes mellitus are advised to always have a healthy lifestyle every day. Control blood sugar in DM patients by regulating diet such as: regulating the amount of food, type of food and frequency of eating hours and doing activities (sports). Non-Communicable Diseases (PTM), including Diabetes Mellitus, has now become a serious threat to global health. Quoted from WHO 2016 data, 70\% of the world's total deaths and more than half of the disease burden. 90-95\% of diabetes cases. Type 2 diabetes, which is largely preventable because it is caused by an unhealthy lifestyle. (Ministry of Health, 2018). Solok City has cases of Diabetes mellitus sufferers in four Puskesmas where there are 284 KTK Puskesmas working areas, while the number of visits to Type II Diabetes mellitus sufferers in the KTK Puskesmas work area is 50 people. Based on the results of research that has been carried out in the Working Area of the KTK Kota Solok Health Center, it was found that more than part (66\%) of the respondents 'blood sugar levels were abnormal (high), more than part (64\%) of the respondents' diet was not appropriate and more than some $(60 \%)$ respondents do not do physical activity regularly. There is a relationship between a diet that is not in accordance with abnormal blood sugar levels and there is a relationship that does not do physical activity with abnormal (high) blood sugar levels in the Working Area of the KTK Kota Solok Health Center. It is hoped that health workers will remind people with Type II Diabetes Mellitus, about the importance of dietary regulation in controlling blood sugar levels and carrying out regular physical activity (exercise) so that it can help in controlling blood sugar levels so that blood sugar levels can be controlled.
\end{abstract}

Keywords: Diet, Physical Activity, Control of Blood Sugar Levels

Abstrak: Pengendalian kadar gula darah merupakan tujuan utama dari intervensi keperawatan yang akan dilakukan pada pasien Diabetes Mellitus. Penderita diabetes melitus disarankan untuk selalu menerapkan pola hidup sehat setiap hari. Kontrol gula darah pada pasien DM dengan cara mengatur pola makan seperti : mengatur jumlah makanan, jenis makanan dan frekuensi jam makan serta melakukan aktivitas (olahraga). Penyakit Tidak Menular (PTM), termasuk Diabetes Mellitus, kini telah menjadi ancaman serius bagi kesehatan global. Dikutip dari data WHO 2016, $70 \%$ dari total kematian dunia dan lebih dari setengah beban penyakit. 90-95\% kasus diabetes. Diabetes tipe 2 yang sebagian besar dapat dicegah karena disebabkan oleh gaya hidup yang tidak sehat. (Kementerian Kesehatan, 2018). Kota Solok memiliki kasus penderita Diabetes mellitus di empat Puskesmas dimana terdapat $284 \mathrm{KTK}$ wilayah kerja Puskesmas, sedangkan jumlah kunjungan penderita Diabetes Melitus Tipe II di wilayah kerja Puskesmas KTK sebanyak 50 orang. Berdasarkan hasil penelitian yang telah dilakukan di Wilayah Kerja Puskesmas KTK Kota Solok ditemukan bahwa lebih 
dari sebagian (66\%) kadar gula darah responden tidak normal (tinggi), lebih dari sebagian (64\%) pola makan responden tidak sesuai dan lebih dari sebagian $(60 \%)$ responden tidak melakukan aktivitas fisik secara teratur. Ada hubungan antara pola makan yang tidak sesuai dengan kadar gula darah yang tidak normal dan ada hubungan yang tidak melakukan aktivitas fisik dengan kadar gula darah yang tidak normal (tinggi) di Wilayah Kerja Puskesmas KTK Kota Solok. Diharapkan kepada petugas kesehatan untuk mengingatkan penderita Diabetes Mellitus Tipe II, tentang pentingnya pengaturan pola makan dalam mengontrol kadar gula darah dan melakukan aktivitas fisik (olahraga) secara teratur sehingga dapat membantu dalam pengendalian kadar gula darah sehingga kadar gula darah dapat dikendalikan.

Kata kunci: Diet, Aktivitas Fisik, Pengendalian Kadar Gula Darah Blood

\section{A. Pendahuluan}

Tujuan pembangunan kesehatan menuju Indonesia sehat 2025 adalah meningkatkan kesadaran, kemauan, dan kemampuan hidup sehat bagi setiap orang agar peningkatan derajat kesehatan masyarakat yang setinggi-tingginya dapat terwujud melaui terciptanya masyarakat,bangsa dan Negara Indonesia yang ditandai dengan penduduknya yang hidup dengan prilaku dan hidup dalam lingkungan sehat, memiliki kemampuan untuk menjangkau pelayanan kesehatan yang bermutu, secara adil dan merata serta memiliki derajat kesehatan yang setinggi-tingginya diseluruh wilayah Republik Indonesia. (Depkes RI, 2009). Upaya kesehatan diselenggarakan dengan pengutamaan pada upaya pencegahan (preventif), dan peningkatan kesehatan (promotif), bagi segenap warga Negara Indonesia, tanpa mengabaikan upaya penyembuhan penyakit (kuratif), dan pemulihan kesehatan, diperlukan pula upaya peningkatan lingkungan yang sehat, salah satu kesehatan dalam upaya preventif (pencegahan) adalah penyakit DM. ( Depkes RI,2009).

Penyakit Tidak Menular (PTM) termasuk diabetes, saat ini telah menjadi ancaman serius kesehatan global. Dikutip dari data WHO 2016, $70 \%$ dari total kematian di dunia dan lebih dari setengah beban penyakit. 90-95\% dari kasus Diabetes adalah Diabetes Tipe 2 yang sebagian besar dapat dicegah karena disebabkan gaya hidup yang tidak sehat. (Kemenkes RI, 2018). Diabetes Melitus adalah penyakit kronis serius yang terjadi karena pankreas tidak menghasilkan cukup insulin ( hormone yang mengatur gula darah atau glukosa ), atau ketika tubuh tidak dapat secara efektif menggunakan insulin yang dihasilkannya. Diabetes adalah masalah kesehatan masyarakat yang tidak penting, menjadi salah satu dari empat penyakit tidak menular prioritas yang menjadi target tindak lanjut oleh para pemimpin dunia.Jumlah kasus prevalensi diabetes terus meningkat selama beberapa dekade terakhir.( WHO Global Report, 2016).

Jumlah penderita diabetes mengalami peningkatan signifikan dari tahun ke tahun. Menurut International Diabetes Federation (IDF) 2017 menyatakan bahwa 425 juta dari total populasi seluruh dunia, atau sekitar 8,8 persen orang dewasa berumur 20-79 tahun merupakan penderita diabetes. Data tersebut juga mengungkapkan bahwa menempati peringkat ke-6 sebagai jumlah penderita diabetes dewasa tertinggi di dunia dengan total lebih dari 10,3 juta orang. Angka ini diprediksi akan terus mengalami peningkatan dan mencapai 16, 7 juta pada tahun 2045.(International Diabetes Federation 2017). Indonesia, berdasarkan data Riset Kesehatan Dasar (Riskesdas) tahun 2018, secara umum angka prevalensi diabetes mengalami peningkatan cukup signifikan selama lima tahun terakhir. Di tahun 2013, angka prevalensi diabetes pada 
orang dewasa mencapai 6,9 persen, dan di tahun 2018 angka terus melonjak menjadi 8,5 persen.( Riskesdas,2018)

Dinas kesehatan Sumbar mencatat tahun 2018 sebanyak 245.105 atau sekitar 13,72\% masyarakat menderita diabetes melitus (DM). Jika dilihat dari data tahun 2017 penderita DM hanya mencapai 6\% lebih. atau sekitar 6 ribuan. Angka ini menunjukkan adanya peningkatan yang signifikan. Sedangkan di Kota Solok kasus penderita penyakit Diabetes melitus di empat Puskesmas dimana terdapat di Wilayah Kerja Puskesmas KTK sebanyak 284 oramg, sedangkan jumlah kunjungan penderita Diabetes melitus Tipe II diwilayah Kerja Puskesmas KTK sebanyak 50 orang. Cara hidup masa kini telah mengubah kebiasaan banyak orang. Perubahan pola hidup serba instan yang ingin langsung ada dan pola makan yang serba instan pula. Problem utama penyakit diabetes melitus adalah mengendalikan pola makan yang awalnya sebagai penyebab paling utama seseorang bisa terkena diabetes, bisa lebih lambat atau lebih cepat hadir ke dalam kehidupan. Perubahan struktur masyarakat dari pola agraris kemasyarakat industri banyak memberikan andil terhadap perubahan gaya hidup dapat memicu peningkatan penyakit tidak menular, Salah satunya Diabetes Melitus (Hamdan,Bustan et al ,2007).

\section{B. Metodologi Penelitian}

Jenis penelitian dalam penelitian ini adalah deskriptif analitik dengan menggunakan desain cross Sectional, yaitu penelitian dilakukan dalam waktu pengukuran / pengamatan variabel independen dan dependen dalam waktu bersamaan. Dalam penelitian ini yang menjadi variabel independen adalah Pola Makan dan Aktivitas Fisik, variabel dependen adalah Pengendalian Kadar Gula Darah pada Penderita Diabetes Mellitus Tipe II di Wilayah Kerja Puskesmas KTK Kota Solok.

\section{Hasil dan Pembahasan}

\section{Karakterisitik Umur Responden}

Umur menurut Depkes RI (2009) dikelompokkan menjadi kelompok Dewasa Akhir (31-45 Th), Dewasa Tengah (46-59 Th) dan Lansia ( $\geq 60 \mathrm{Th}$ )

Tabel 1 Distribusi Frekuensi Responden Berdasarkan Kelompok Umur di Wilayah Kerja Puskesmas KTK Kota Solok

\begin{tabular}{|l|l|l|ll|}
\hline No & Kelompok Umur & f & \% & \\
\hline 1 & Dewasa Akhir (31-45 Tahun) & 21 & $42 \%$ & \\
2 & Dewasa Tengah (46-59 Tahun) & 5 & $10 \%$ & \\
3 & Lansia ( $\geq$ 60 Tahun) & 24 & $48 \%$ & \\
\hline \multicolumn{2}{|c|}{ Jumlah } & $\mathbf{5 0}$ & & $\mathbf{1 0 0}$ \\
\hline
\end{tabular}

Berdasarkan tabel diatas diketahui bahwa kurang dari sebagian (48\%) responden berada pada kelompok umur lansia ( $\geq 60$ Tahun)

\section{Pendidikan}

Pendidikan responden menurut Kemendiknas (2003) dikelompokan menjadi pendidikan dasar ( SD-SLTP), pendidikan menengah (SMA) dan pendidikan tinggi (Perguruan Tinggi) 
Tabel 2 Distribusi Frekuensi Responden Berdasarkan Tingkat Pendidikan di Wilayah Kerja Puskesmas KTK Kota Solok

\begin{tabular}{|l|l|l|l|}
\hline No & Pendidikan & $\mathbf{f}$ & \% \\
\hline 1 & Pendidikan dasar (SD- & 32 & $64 \%$ \\
2 & SMP) & 14 & $28 \%$ \\
3 & Menengah (SMA) & 4 & $8 \%$ \\
& Tinggi (PT) & & \\
\hline \multicolumn{2}{|c|}{ Jumlah } & $\mathbf{5 0}$ & \\
\hline
\end{tabular}

Berdasarkan tabel diatas diketahui bahwa lebih dari sebagaian (64\%) responden berpendidikan dasar (SD - SLTP).

\section{Pekerjaan}

Pekerjaan responden menurut Handoko (2016) terdiri dari ibu rumah tangga, pegawai, petani, dan wiraswasta

Tabel 3 Distribusi Frekuensi Responden Berdasarkan Jenis Pekerjaan di Wilayah Kerja Puskesmas KTK Kota Solok

\begin{tabular}{|c|c|c|c|}
\hline No & Pekerjaan & $\mathbf{F}$ & $\%$ \\
\hline 1 & IRT & 22 & $44 \%$ \\
\hline 2 & PNS & 2 & $4 \%$ \\
\hline 3 & Petani & 18 & $36 \%$ \\
\hline 4 & Wiraswasta & 8 & $16 \%$ \\
\hline \multicolumn{2}{|r|}{ Jumlah } & 50 & 100 \\
\hline
\end{tabular}

Berdasarkan tabel diatas diketahui bahwa kurang dari sebagian (44\%) responden bekerja sebagai ibu rumah tangga (IRT)

\section{Hasil Univariat}

Kadar Gula Darah

Distribusi Frekuensi Responden Berdasarkan Kadar Gula Darah di Wilayah Kerja Puskesmas KTK Kota Solok

\begin{tabular}{|c|c|c|c|}
\hline No & Kadar Gula Darah & $\mathbf{F}$ & $\%$ \\
\hline $\begin{array}{l}1 \\
2\end{array}$ & $\begin{array}{l}\text { Normal } \\
\text { Tidak Normal (Tinggi) }\end{array}$ & $\begin{array}{l}17 \\
33\end{array}$ & $\begin{array}{l}34 \% \\
66 \%\end{array}$ \\
\hline \multicolumn{2}{|r|}{ Jumlah } & 50 & 100 \\
\hline
\end{tabular}

Berdasarkan tabel diatas diketahui bahwa lebih dari sebagian (66\%) kadar gula darah responden tidak normal (tinggi)

\section{Pola Makan}

Distribusi Frekuensi Responden Berdasarkan Pola Makan di Wilayah Kerja Puskesmas KTK Kota Solok

\begin{tabular}{|l|l|ll|ll|}
\hline No & Pola Makan & f & \% & \\
\hline 1 & Sesuai & 18 & & $36 \%$ & \\
2 & Tidak sesuai & 32 & & $64 \%$ & \\
\hline \multicolumn{2}{|c|}{ Jumlah } & \multicolumn{2}{|c|}{$\mathbf{5 0}$} & \multicolumn{1}{|c|}{} & $\mathbf{1 0 0}$ \\
\hline
\end{tabular}

Berdasarkan tabel diatas diketahui bahwa lebih dari sebagian (64\%) pola makan responden tidak sesuai. 


\section{Aktivitas Fisik (Olahraga)}

Distribusi Frekuensi Responden Berdasarkan Aktivitas fisik (Olahraga) di Wilayah Kerja Puskesmas KTK Kota Solok

\begin{tabular}{|c|c|c|c|}
\hline No & Aktivitas Fisik & $\mathbf{f}$ & $\%$ \\
\hline 1 & Dilakukan & 20 & $40 \%$ \\
\hline 2 & Tidak dilakukan & 30 & $60 \%$ \\
\hline \multicolumn{2}{|r|}{ Jumlah } & 50 & $\overline{100}$ \\
\hline
\end{tabular}

Berdasarkan tabel diatas diketahui bahwa lebih dari sebagian $(60 \%)$ responden tidak melakukan aktivitas fisik.

\section{Hasil Bivariat}

Hubungan Pola Makan dengan Pengendalian Kadar Gula Darah di Wilayah Kerja Puskesmas KTK Kota Solok

Distribusi Frekuensi Responden Berdasarkan Pola Makan dengan Pengendalian Kadar Gula darah di Wilayah Kerja Puskesmas KTK Kota Solok

\begin{tabular}{|l|c|c|c|c|c|c|}
\hline \multirow{3}{*}{ Pola Makan } & \multicolumn{6}{|c|}{ Pengendalian kadar Gula darah } \\
\cline { 2 - 7 } & \multicolumn{2}{|c|}{ Normal } & \multicolumn{2}{c|}{ Tidak Normal } & \multicolumn{2}{c|}{ Total } \\
\cline { 2 - 7 } & $\mathbf{f}$ & $\mathbf{\%}$ & $\mathbf{f}$ & $\mathbf{\%}$ & $\mathbf{f}$ & $\mathbf{\%}$ \\
\hline Sesuai & 13 & $72,2 \%$ & 5 & $27.7 \%$ & 18 & 100 \\
\hline Tidak Sesuai & 4 & $12.5 \%$ & 28 & $87.5 \%$ & 32 & 100 \\
\hline Jumlah & $\mathbf{1 7}$ & $\mathbf{3 4 \%}$ & $\mathbf{3 0}$ & $\mathbf{6 6 \%}$ & $\mathbf{5 0}$ & $\mathbf{1 0 0}$ \\
\hline
\end{tabular}

$$
P=0,000 \quad \text { OR }=18,200
$$

Hasil analisis antara pola makan dengan pengendalian kadar gula darah didapatkan dari 32 responden, $28(87,5 \%)$ yang pola makan tidak sesuai dengan kadar gula darah tidak normal (tinggi). Sedangkan dari uji statistik diperoleh $p$ value $0,000<$ 0,05 yang artinya ada hubungan antara pola makan yang tidak sesuai dengan kadar gula darah tidak normal (tinggi) di Wilayah Kerja Puskesmas KTK Kota solok.

\section{Hubungan Aktivitas Fisik dengan Pengendalian Kadar Gula Darah di Wilayah Kerja Puskesmas KTK Kota Solok}

Distribusi Frekuensi Responden Berdasarkan Aktivitas Fisik dengan

Pengendalian Kadar Gula Darah di Wilayah Kerja Puskesmas KTK Kota Solok

\begin{tabular}{|c|c|c|c|c|c|c|}
\hline \multirow{2}{*}{ Aktivitas } & \multicolumn{6}{|c|}{ Pengendalian kadar Gula darah } \\
\cline { 2 - 7 } \multicolumn{1}{c|}{ Fisik } & \multicolumn{2}{|c|}{ Normal } & \multicolumn{2}{c|}{ Tidak Normal } & \multicolumn{2}{c|}{ Total } \\
\cline { 2 - 7 } & $\mathbf{f}$ & $\mathbf{\%}$ & $\mathbf{f}$ & $\mathbf{\%}$ & $\mathbf{f}$ & \% \\
\hline Dilakukan & 12 & $60,0 \%$ & 8 & $40,0 \%$ & 20 & 100 \\
\hline Tidak Dilakukan & 5 & $16,6 \%$ & 25 & $83,3 \%$ & 30 & 100 \\
\hline Jumlah & $\mathbf{1 7}$ & $\mathbf{3 4 \%}$ & $\mathbf{3 3}$ & $\mathbf{6 6 \%}$ & $\mathbf{5 0}$ & $\mathbf{1 0 0}$ \\
\hline
\end{tabular}

$$
P=0,004 \quad \text { OR }=7,500
$$

Hasil analisis antara aktivitas fisik dengan pengendalian kadar gula darah didapatkan dari 30 responden, $25(83,3 \%)$, yang tidak melakukan aktivitas fisik dengan kadar gula darah tidak normal (tinggi). Sedangkan dari uji statistik diperoleh $p$ value $0,004<$ 
0,05 yang artinya ada hubungan yang tidak melakukan aktivitas fisik dengan kadar gula darah tidak normal (tinggi) di Wilayah Kerja Puskesmas KTK Kota solok

\section{Hubungan Pola Makan dengan Kadar Gula Darah}

Berdasarkan uji statistik diperoleh $p$ value $0,000<0,05$ yang artinya ada hubungan antara pola makan yang tidak sesuai dengan kadar gula darah tidak normal (tinggi) di Wilayah Kerja Puskesmas KTK Kota solok. Pola makan adalah suatu cara tertentu dalam mengatur jadwal, jumlah, jenis asupan makanan dengan maksud untuk mempertahankan kesehatan, status gizi, serta pencegahan atau membantu proses penyembuhan. (Depkes, 2009). Pola makan yang baik harus dipahami oleh penderita Diabetes Mellitus Tipe II dalam pengaturan pola makan sehari-hari. Pola makan memegang peranan penting bagi penderita Diabetes Mellitus, seseorang yang tidak bisa mengatur pola makan dengan mengatur $3 \mathrm{~J}$ (jadwal, jumlah dan jenis), maka hal ini akan menyebabkan penderita Diabetes Mellitus mengalami peningkatan kadar gula darah.(Suiraoka, 2012).

Kenyataan yang ditemukan dilapangan sebagian besar $(87.5 \%)$ yang pola makan tidak sesuai menyebabkan kadar gula darah tidak normal (tinggi), hal ini dikarenakan responden masih mengkonsumsi makannan yang banyak mengandung karbohidrat atau gula yang dapat memicu kandungan kadar gula darah tidak terkontrol dan juga belum sesuainya dalam mengatur jadwal makan. Oleh karena itu, penderita Diabetes mellitus Tipe II perlu menjaga pengaturan pola makan dalam rangka pengendalian kadar gula darah sehingga kadar gula darahnya dapat terkontrol.

\section{Hubungan Aktivitas Fisik dengan Kadar Gula Darah}

Berdasarkan uji statistik diperoleh $p$ value $0,004<0,05$ yang artinya ada hubungan antara yang tidak melakukan aktivitas fisik dengan kadar gula darah tidak normal (tinggi) di Wilayah Kerja Puskesmas KTK Kota Solok. Aktivitas fisik sebagai salah satu pengobatan untuk penderita Diabetes Mellitus, oleh karena itu aktivitas fisik (Olahraga) menjadi pertimbangan dalam memberikan manfaat dalam membantu pengaturan kadar gula darah pada penderita Diabetes Melitus Tipe II. Aktivitas fisik adalah pergerakan tubuh yang menyebabkan pengeluaran tenaga (Pembakaran kalori). Aktivitas fisik dapat dilakukan oleh partisipan sebagai salah satu upaya pencegahan dan pengendalian kadar gula darah. Jika aktivitas fisik yang dilakukan sangat minim akan membuat sistem sekresi tubuh berjalan lambat. Akibatnya terjadilah penumpukan lemak di dalam tubuh lambat laun berat badan menjadi berlebih dan dapat mengarah terjadinya penyakit Diabetes Melitus.

Kenyataan yang ditenukan dilapangan didapatkan sebagian besar $(83,3 \%)$, responden yang tidak melakukan aktivitas fisik (olah raga) dengan kadar gula darah tidak normal (tinggi), hal ini dikarenakan responden belum melakukan aktivitas fisik (olahraga) dan sebagian kecil responden sudah melakukan aktivitas fisik namun masih belum teratur, oleh karena itu dianjurkan pada penderita Diabetes Melitus Tipe II dapat melakukan aktivitas fisik secara teratur sehingga dapat membantu mengendalikan kadar gula darahnya.

\section{Penutup}

Berdasarkan hasil penelitian yang telah dilakukan di Wilayah Kerja Puskesmas KTK Kota solok, didapatkan lebih dari sebagian (66\%) kadar gula darah responden tidak normal (tinggi), lebih dari sebagian (64\%) pola makan responden tidak sesuai dan lebih dari sebagian (60\%) responden tidak melakukan aktivitas fisik secara teratur. 
Terdapatnya hubungan antara pola makan yang tidak sesuai dengan kadar gula darah tidak normal dan ada hubungan yang tidak melakukan aktivitas fisik dengan kadar gula darah tidak normal (tinggi) di Wilayah Kerja Puskesmas KTK Kota solok. Diharapkan petugas kesehatan untuk mengingatkan kembali kepada penderita Diabetes Melitus Tipe II, tentang pentingnya pengaturan pola makan dalam pengendalian kadar gula darah, agar kadar gula darah dapat terkontrol, dan melakukan aktifitas fisik (Olahraga) secara terartur sehingga dapat membantu dalam pengendalian kadar gula darah.

\section{Daftar Pustaka}

Bilous Rudy, 2015. Buku Pegangan Diabetes.Edisi 4. Jakarta: Bumi Medika

Depkes RI, 2009. Pembangunan Kesehatan Menuju Indonesia Sehat. Jakarta: Departemen Kesehatan RI

Hariawan, H, 2019. Jurnal Keperawatan Terpadu. Mataram:Poltekkes Mataram

Kemenkes RI, 2018. Penyakit Tidak Menular (PTM). Jakarta: Kementrian Kesehatan RI

Notoadmodjo S, 2010. Metodologi Penelitian Kesehatan. Jakarta: Rineka Cipta

Nursyamsiyah, 2017. Berdamai Dengan Diabetes. Jakarta: Bumi Medika

Padila, 2018. Keperawatan Medikal Bedah. Yogyakarta:Nuha Medika

Kahanti A.M. 2019. Pedoman Pemantauan Glukosa Darah Mandiri. Jakarta: PB PERKENI

R.A.Oetari.2019. Khasiat Obat Tradisional Sebagai Antioksidan Diabetes. Yogyakarta : Rapha Publishing

Riskesda, 2018. Indonesia Data Terbaru Riset Kesehatan Dasar. Jakarta: Riset Kesehatan Dasar

Sari R.N, 2012. Diabetes Melitus ( Dilengkapi dengan Senam DM). Jakarta: Nuhamedika

Suiraoka, 2012. Penyakit Degeratif. Yogyakarta : Nuhamedika. 